\title{
Fazio, M., Launius, C., and Strangleman, T., eds. (2021) Routledge International Handbook of Working-Class Studies. Routledge.
}

\author{
Reviews by Jennifer Forsberg, Isabel Roque, and Rebecca Temple
}

The Handbook of Working-Class Studies, published this year, is such a mammoth volume that most of us are still working our way through it. Since it's too big for one person to review in a timely fashion, we asked three relative newcomers to working-class studies to give us a comprehensive account of the volume. Jennifer Forsberg walks us through Parts I and III on methods and work \& community; Isabel Roque, through Parts IV and VI on culture and activism; and Rebecca Temple, on Parts II and V on education and representation.

\section{Part I: 'Methods and Principles' \& Part III: 'Work and Community' by Jennifer Forsberg}

Part I: 'Methods and principles of research in working-class studies' and Part III: 'Work and Community' map the how and why of working-class studies. The two sections survey and expand the critical map of working-class studies as both positional and site-situated to showcase the social, cultural, historical, and biopolitical pressures of class identity.

As a foundation, Sherry Lee Linkon identifies the scholarly personal narrative as the signature genre of the field, arguing that it showcases a 'hybridized narration' that offers both class memory and analysis, and reflects 'communities and systems' in addition to individual lives (20). This Part I multiplicity and hybridity is best exemplified by Jane A. Van Galen's exploration of First in Our Families, a digital storytelling workshop for first-generation college students that builds community among first-generation students and their peers, while facilitating discussions of equity and inclusivity inside and outside of academic institutions (p. 47; p. 45).

Such multiplying effects are rooted within environmental stimuli, further exemplified in Part III when Geoff Bright details the re-imagining of working-class histories in England's coal field 'Ghost Labs.' These collaborative community/activist/arts workshop(s) narrate both the livedexperience and cultural afterlife of select deindustrialized sites through affective means (p. 215). Participants reveal the 'entangl[ed] reminder of lingering trouble' in class history in the UK and its consistent 'haunting' of eras old and Brexit-new (p. 214).

Similarly, site-specific narration takes precedence in Part I in Christine J. Walley's 'Exit Zero Project', a multimedia and multigenerational ethnographic endeavor in Southeast Chicago. Walley's activist call for innovative modalities aims to promote a meaningful local archive and convincingly highlights the need for diversified methodologies that position class as an everchanging and relational history, identity, and culture (p. 70).

The critical challenge to capture individuals, communities and systems provides the context for Joseph Entin's Part I call to return to Marx-based theoretical anchorings in order to foster new 
modes of learning, telling, and historicizing. However, most provocative is Entin's championing of Sartrean 'seriality,' a concept that aims to make meaning from within multiple social patterns and across stories. In addition to the aforementioned studies, the notion of 'seriality' is instrumental in the study of deindustrialization, a topic that takes priority in Part III, as it offers patterns of change in working-class life through narratives of neoliberal precarity.

Steven High emphasizes the need for oral history as global lived experience in the growing interdisciplinary study of deindustrialization. In doing so, High captures a non-linear historical progression that can recognize both the active 'political resistance' of individuals and the 'cultural persistence or erasure' individuals face (p. 171). These persistent biopolitical patterns of change, as Patrick Korte \& Victor Tan Chen's study suggests, leave deep, traumatic effects on workers into the 21 st century, calling for further study of the demoralizing impact of economic dislocation.

In addition to communities and systems, Part III impressively showcases deindustrialization through the mental and/or physical effects of precarity on the working body: as collective anger expressed by displaced workers in High, as 'industrial disease' in Arthur McIvor (p. 166), and in Kathryn Marie Dudley's direct correlation between deindustrialized Massachusetts and opioid addiction. These narratives of health and wellness address the need for critical study that does not 'reproduce the traumatic effects of deindustrialization' (p. 208). In other words, these scholars offer not just multiplicity and hybridity, but what Dudley calls the 'futurity' of working-class study, working-class communities and working-class life.

Collectively, Parts I and III prove that more malleable methods can call attention to not only the individual narratives of class, but also the material realities of class. This includes the working body, encompassing healthcare, nutrition, and psychiatry. But it also includes site-specific studies like environmental studies or urban planning to better examine what McIvor calls 'work-health cultures' that exhibit influence on the body (p. 190). These offerings promote evolutionary scholarship and activism able to oscillate between story and theory, the local and global, and individuals and their diverse community settings.

\section{Part IV: ‘Cultures’ \& Part VI: ‘Activism’ by Isabel Roque}

In Part IV on 'Working-class cultures,' Jack Metzgar argues that working-class culture is genuine in the sense that it has an internal coherence that is separate and distinct from middle-class culture. In contrast to the middle-class, 'working-class culture emphasizes being and belonging, not achieving and becoming.' And he cites Barbara Jensen as exploring 'the exciting potentials of middle-class becoming and the warm advantages of working-class belonging' (p. 231). Jensen herself examines the devastating psychosocial consequences of precarity among younger workingclass people who have to face more extreme working conditions than previous generations. Betsy Leondar-Wright argues that we need stronger progressive social movements and that building them depends on understanding how class culture differences among activists causes internal misunderstandings and tension. Class inclusiveness requires class consciousness and class identities, i.e., a cultural lens regarding the differences between working-class and middle-class activists. 
According to Jessi Streib, class has a culture, but if people misrecognize their own class position, how can they share a culture? The denial of class cultures belies our experiences, for class shapes how people make sense of the world. Culture includes tastes (likes and dislikes), worldviews (orientation ideas toward the world), dispositions (habitual tendencies), and linguistic styles (how we talk). Sarah Attfield holds that popular culture is an important place to look for working-class representation and working-class expression. She focuses on working-class culture and its misrepresentation in Australian media, which places white and aggressive working-class masculinity at the centre of narratives about what it means to be Australian. Derived from Marx, Weber and Bourdieu's understandings of class, these chapters reveal how class is formed, played out and reproduced in real settings.

In Part VI on 'Activism and Collective Action,' Karen Gaffney focuses on the issue of activism regarding college community, seeking to look at all classes from the point of view of working peoples' lives, experiences, needs, and interests. Terry Easton uses the same approach, focusing on the voices, images, and reflections of a diverse group of day laborers and affordable housing activists. Leslie Hossfeld, E. Brooke Kelly, and Julia F. Waity study workers who labor at the production of healthy food but cannot afford to buy it and the resulting global struggle for food justice. Michael Zweig focuses on race and class, two different structures of power that are mutually determined, stressing that the foundation for a progressive future requires a patriotic, morally based, class-conscious movement that unites all segments of the working class.

Through the use of oral history, Michele Fazio captures the everyday lives of citizens who have endured the spiralling effects of job loss and economic precarity since the 1980s. Fazio stresses the importance of this project for strengthening the academic skills of her students and for developing a working-class studies activist approach to service-learning. Isabel Roque explores new forms of organising from below, especially cyber-activism. In the 21st century, a new class power, activism, and unionism are being rebuilt in the service sector, especially among workers who deal with digital platforms. This is bringing new synergies at a national and international level, reinventing the sense of traditional unionism, and engaging with other social struggles for labor and human rights. Joseph Varga examines how unions and members of the working class and their supporters are establishing repertoires of contention to meet the needs of contemporary struggles over worker's rights. He stresses that scholars of working-class activism, union organizing, and working-class culture need to analyse the post-Fordist period with a critical eye regarding the repertoires of contention used in the struggle for decent living standards and workplace voice.

These essays are an extremely valuable resource for working-class studies activists, academics and students, seeking to bring a more inclusive approach regarding class consciousness and solidarity, and breaking down traditional gender, race, and class divisions.

\section{Part II: 'Education' \& Part V: 'Representations' by Rebecca Temple}

Relying upon the myth of the American Dream, the institution of public education appeals to students who wish to pursue their individual goals, advance in social influence, or contribute to the prosperity of their communities. Part II of the Handbook invalidates this mythological ideology 
by exploring the deeply engrained cultural divisions and discriminatory practices in education that often thwart working-class and first-generation students from realizing this dream.

The current standard policies and procedures in education reflect the dominant middle-class culture built upon the prejudice of classism. Classism is a powerfully subversive force that is often overlooked in American society due to the prevailing belief that an individual can determine their success by relying upon their own strength. The writers of the essays in 'Class and Education' completely discredit this flawed ideology. Through analysis of the psychological conflicts of cultural mismatching and isolation, the debilitating physical effects of stress, and the financial anxieties that routinely impede working-class and first-generation students in academia, each writer provides evidence to support the argument that we 'need an alternative way to think about education' (p. 80).

Drawing upon both extensive scholarly research and their own personal experiences and applications, the essayists provide strategies designed to fight the cyclical reproduction of social class in school and after graduation. For example, scholars Colleen Clements and Mark Vagle propose five principles of social class-sensitive pedagogy to examine the systemic problem of poverty; Lisa Kirby shows how 'content and pedagogy' are crucial to implementing Workin- Class Studies in a curriculum; Bettina Spencer offers several approaches to battling classism on campuses; and Colby King and Sean McPherson present the success of the class coalition at Bridgewater State University. Deborah Warnock's essay ends this section with re-examination of the many issues that exacerbate social class inequalities in education but, as Diane Reay hopes, current political climates and increasing awareness will provide opportunities to make changes in public education that will grant us our 'alternative view of education,' one that empowers everyone in its inclusivity and unity.

Visual, literary, and dramatic artistic creations shape, reflect, and communicate the values and concerns and establish the identity of a community. Section V of the Handbook presents scholarship that investigates a wide range of cultural production and depiction of the workingclass in various media with an attempt to 'expand the commons,' as Janet Zandy suggests (p. 354).

In her chapter entitled, 'Mapping working-class art,' Zandy unpacks the 'intersecting and shaping elements' that contribute to the almost limitless aspects of working-class art, asking questions such as: 'How does working-class art work?,' 'How can we start to see art making through the lens of a working-class perspective?' and 'How does it reflect, perhaps serve, the interests of ordinary people?' (p. 345). The essays in this collection contribute some answers to these questions, and through analysis of artistic representation, they expand the awareness of the culture and realties of working-class life.

The struggles between the working-class precariat and forces of power are often embattled in spaces that are transitory, unstable, unwelcoming, and in some instances, closed. Christiane Scholte analyzes two texts that narrate the lives of Asian 'petro-migrant' taxi-drivers among Dubai's urban landscape, in private flats, and through well-known tenement houses. Tom Zaneillo examines five significant movements of film that illustrate the lives of American migrant workers, Chinese internal labor migrants, workers in waste and toxic zones, the working class directly affected by Wal-Mart, and fictionalized workers in virtual reality. Carol Quirke challenges the 
supposed absence of working-class representation in post-Depression documentary by exploring the photography of Arthur Leipzig, Dan Weiner, and Robert Frank.

Continuing this notion of 'things left out,' Ben Clarke insists that working-class literature has been unfairly excluded from academia and offers suggestions for ways these texts can be read differently to re-define what counts as literary. Simon Lee accentuates the importance of setting in films that depict working-class lives as it provides tension between the grit of the individual character's tenacity and the physical grimy grit of the spaces in which they work and live. From the space of prison, Nathaniel Heggins Bryant calls for solidarity between workers on 'both sides of the wall' with his argument that US prison writing and literature are forms of 'intellectual labor and ... potential sources of resistance' (p. 381). And, finally, Jennifer Forsberg examines three millennial television sit-coms that situate working-class female bodies as vulnerable and marketable but mask social and economic inequality and division.

\section{Reviewer Bios}

Jennifer Forsberg is a senior lecturer in the College of Architecture, Arts and Humanities at Clemson University in South Carolina.

Isabel Roque is a researcher at the Centre for Social Studies, University of Coimbra, a member of the Call Center Workers Union, and a Ph.D. candidate in Labor Relations - Sociology at the University of Coimbra in Portugal.

Rebecca Temple is a high school English teacher in Madison, Mississippi, and a graduate student in Rhetoric and Composition at Texas A\& M University-Commerce. 